\title{
THE SURFACE ANATOMY OF TRANSVERSE SINUS IN RELATION TO INION TO ROOT OF ZYGOMA LINE- AN AUTOPSY STUDY
}

\section{Krishnakumar P1}

${ }_{1}^{1}$ Assistant Professor, Department of Neurosurgery, Government TD Medical College, Alappuzha, Kerala, India.

\section{ABSTRACT}

\section{BACKGROUND}

The purpose of our study is to see whether a line marked on the surface of skull connecting the inion to root of zygoma can be reliably used as a surface landmark to ascertain the position of transverse sinus.

\section{METHODS}

This was a descriptive study carried out on 25 adult bodies, which underwent autopsy at our institution. After the vertex of skull is removed, two points are marked on the outside of skull-one on the inion, and other at the root of zygoma. A line is marked connecting these two points- the Inion-Zygoma line (I-Z line). Two points corresponding to proximal and distal transverse sinus are marked on the outside of skull. The distance between these two points and the previous line are measured.

\section{RESULTS}

Proximal and distal transverse sinuses were found to be above the I-Z line on both sides.

\section{CONCLUSIONS}

The I-Z line can be reliably used to predict the position of the transverse sinus while doing posterior fossa craniotomies.

HOW TO CITE THIS ARTICLE: Krishnakumar P. The surface anatomy of transverse sinus in relation to inion to root of zygoma line- an autopsy study. J. Evolution Med. Dent. Sci. 2019;8(14):1128-1130, DOI: 10.14260/jemds/2019/250

\section{BACKGROUND}

Posterior fossa craniotomies and craniectomies are commonly used by neurosurgeons to approach infratentorial lesions. While doing such procedures there is a chance to violate and go to supratentorial compartment if the burr holes are not appropriately placed. There remains a chance to injury to critical structures such as transverse sinus and torcula which can be devastating. So it is highly imperative that the surface land mark of the transverse sinus be borne in mind before embarking on such procedures. Once the patient is placed in prone position and draped the naive neurosurgeon can get disoriented and totally lost regarding the surface markings of the critical structures. Volumes of literature have been published regarding the surface landmark for strategic burr hole for retrosigmoid craniotomy, but regarding the surface anatomy of the transverse sinus only a few literature have been published.(1,2,3) In our study we attempt to see whether a line marked on the surface of the skull connecting the inion and root of zygoma (I-Z line) can be reliably used as a surface land mark for the transverse sinus.

\section{METHODS}

The study was approved by institutional ethics committee. Ours was a descriptive study carried out on 25 adult bodies, which underwent autopsy in our institution. Consent was taken from the patient's attendants before the study.

'Financial or Other Competing Interest': None.

Submission 13-02-2019, Peer Review 22-03-2019,

Acceptance 29-03-2019, Published 08-04-2019.

Corresponding Author:

Krishnakumar $P$,

Assistant Professor,

Department of Neurosurgery,

Government TD Medical College,

Alappuzha,

Kerala, India.

E-mail: drpkrishnan77@gmail.com

DOI: $10.14260 /$ jemds $/ 2019 / 250$
For the purpose of the study the proximal transverse sinus was defined as the part just adjacent to torcula on the corresponding side and distal transverse sinus as just near the transverse sigmoid junction on the corresponding side. Those patients with previous craniotomies and craniovertebral junction anomalies were excluded from the study.

During the autopsy the vertex of the skull is removed close to the posterior fossa. Two points on the skull were marked, the first being the inion and the second the root of zygoma. A line is marked connecting the inion and root of zygoma. A divider is inserted past the craniotomy in such a manner that one limb just touches the upper margin of proximal transverse sinus (Fig. 1). The corresponding point of the other limb of the divider on the outside of the skull is marked (Fig. 2). The same procedure is repeated for distal transverse sinus also. The vertical distance between the marked points and the IZ line drawn on the outside of the skull is measured.

All data were analysed using SPSS software version 16.0 (SPSS Inc, Chicago, Illinois, USA).Descriptive statistics were presented as means with standard deviation for continuous variables and as percentages for categorical variables.

\section{RESULTS}

A total of 25 bodies were studied (50 sides).In midline just adjacent to the torcula the upper part of the transverse sinus was found at an average of $13.4 \mathrm{~mm}$ (Median 13.4, range 1214.8) above the IZ line on right side and an average of 12.5 mm (Median 12.7, range 11.2-13.4) above the same on left side. The distal part of transverse sinus was found to be at a mean distance of $14.1 \mathrm{~mm}$ (median 14.3, range 13-14.8) above the IZ line on right side and a mean of $13.8 \mathrm{~mm}$ (Median $13.4 \mathrm{~mm}$, range 11.2-13.8)above the same on left side. The mean width of the proximal transverse sinus was $8.5 \mathrm{~mm}$ (Median $8.5 \mathrm{~mm}$, range $8.0-9.1 \mathrm{~mm}$ ) on right side and $8.2 \mathrm{~mm}$ (Median $8.3 \mathrm{~mm}$, range 8.1-8.6 $\mathrm{mm}$ ) on left side. 

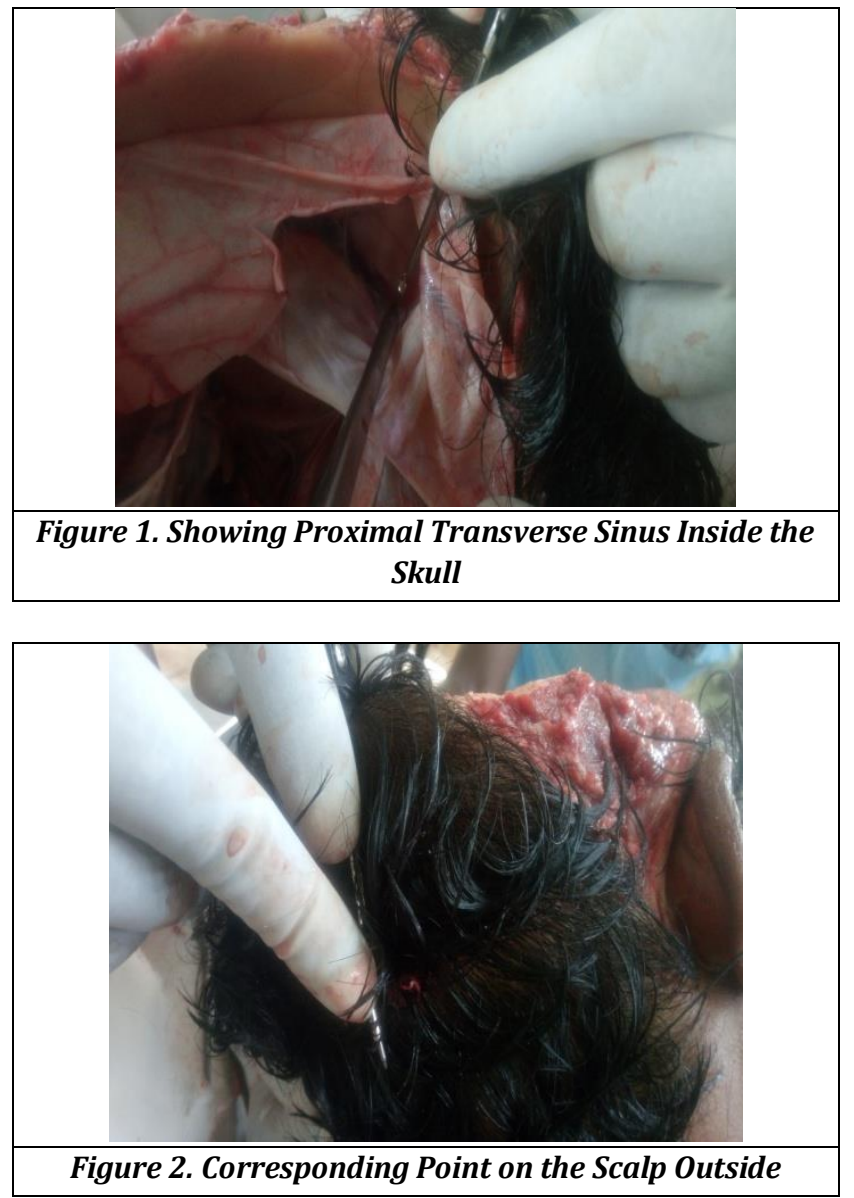

\section{DISCUSSION}

Retrosigmoid and suboccipital craniotomies are routinely used by neurosurgeons to access the lesions of the posterior fossa. Since the entry to posterior is restrained by transverse and sigmoid sinuses, it is highly imperative that the exact location of these venous sinuses must be known to neurosurgeons while doing these procedures. External land marks on the skin surface are of immense help for the surgeon. Several studies have come up with different external landmarks for the transverse sinus -the point of insertion of semispinalis capitis muscle, the superior nuchal line (SNL) etc. Traditionally asterion has been used as an external land mark for transverse sigmoid junction (TSJ). In our study we demonstrated that an imaginary line from the inion to root of zygoma (I-Z line) can be used to mark the transverse sinus.

Tubbs R.S et al(4) have demonstrated that the most accurate external landmark that can be estimated in reliably predicting the internal placement of proximal transverse sinus is the point of insertion of semispinalis capitis muscle (MSC).They measured the distance between the apex of insertion of fibres of MSC and corresponding internally located transverse sinus. The distance on left side ranged from 0 to $6 \mathrm{~mm}$ with a mean of $2.6 \mathrm{~mm}$ and on right side ranged from 0 to $10 \mathrm{~mm}$ with a mean of $3.5 \mathrm{~mm}$. Proximal transverse sinus for the purpose of study was defined as segment of sinus close to torcular herophili. Day JD et al(5) has described that a line drawn from the zygoma root to the inion reliably located the rostro caudal level of transverse sinus in all their specimens. They have equated this line equivalent to superior nuchal line. Avci et al(6) in their study showed that the upper margin of SNL was found to range from 1.5 to 14 $\mathrm{mm}$ inferior to the lower margin of lateral transverse sinus. He concluded that the SNL was a more accurate landmark to localise the distal transverse sinus and that Asterion was not reliable to localize transverse sigmoid junction. Hwang et al(7) in their study however elaborated that the SNL did not correspond to the IZ line in all cases and that IZ line was always found below the SNL. They pointed out that the transverse sinus roughly coursed between the SNL and IZ line as it moved laterally from the proximal to distal transverse sinus. At the asterion the lower edge of the TS was found roughly $5 \mathrm{~mm}$ above the IZ line on right and $6.4 \mathrm{~mm}$ above the same on left. Bozbuga et al(8) studied dry human skulls and observed that SNL roughly parallels below the lower margin of transverse sinus in all specimens. They found that the mean distance between the SNL and lower transverse sinus was $7.9 \mathrm{~mm} \mathrm{n}$ the right and $8.1 \mathrm{~mm}$ on the left. In our study also the SNL was cranial to the IZ line in all cases. Many of the studies conducted were on dry skull bones or cadaveric studies where the sinus tends to contract whereas our study is an autopsy study where this process has not occurred. In fact the SNL is produced by the pull of several nuchal muscles and has nothing to do with the transverse sinus on the inside.

The asymmetry of sinuses on two sides were also studied. We did not have an aplastic sinus. Nine out of twenty five sinuses on the left side were less than $0.5 \mathrm{~cm}$ in size while 3 sinuses on the right were less than $0.5 \mathrm{cms}$. The transverse sinuses are not equal in size or level. The right transverse sinus is usually larger and placed more inferiorly than the left transverse sinus. Alper et al(9) used time of flight magnetic resonance venography in assessing the normal anatomy of dural venous sinuses. They found transverse sinus aplasia in $20 \%$ of cases on left side and $4 \%$ on the right side. Both sinuses were symmetric in $31 \%$ of cases. Sometimes transverse sinus can be duplicated.

Chottiwat $\mathrm{T}$ et al(10) have studied the relationship of the IZline to the transverse sinus on both sides. The transverse sinus was marked along 25\%, 50\%, and $75 \%$ from the midline. The projected IZ line was evaluated to see whether it was positioned exactly over the transverse sinus. The distance of the inferior margin of the sinus from the projected line was measured along the three points. In $95 \%$ of case they found that the projected line was below the inferior margin of transverse sinus. The distance between the projected line and the sinus margins gradually increased as one leaves the midline towards lateral side. In our study we have used the superior margin of the TS which also included their width of the transverse sinus. Hwang et al in their study have found the mid transverse sinus to be cranial on average $3.5 \pm 5.7$ $\mathrm{mm}$ on the right and $3.2 \pm 6 \mathrm{~mm}$ cranial on the left, to the superior nuchal line.

\section{CONCLUSIONS}

I-Z line can be used reliably by neurosurgeons as a surface landmark to predict the position of the transverse sinus, while doing suboccipital craniotomies. The results are in tune with other anatomical studies but the difference is that, being an autopsy study, there was not much drying and shrinking of tissues. However, the potential for measurement error has been a major limitation of our study. 


\section{REFERENCES}

[1] Tubbs RS, Loukas M, Shoja MM, et al. Surface landmarks for the junction between the transverse and sigmoid sinuses: application of the "strategic" burr hole for suboccipital craniotomy. Neurosurgery 2009;65(Suppl 6):S37-41.

[2] Raso JL, Gusmao SN. A new landmark for finding the sigmoid sinus in suboccipital craniotomies. Neurosurgery 2011;68(Suppl Operative):1-6.

[3] Ucerler H, Govsa F. Asterion as a surgical landmark for lateral cranial base approaches. J Craniomaxillofac Surg 2006;34(7):415-20.

[4] Tubbs RS, Salter G, Oakes WJ. Superficial surgical landmarks for the transverse sinus and torcular herophili. J Neurosurg 2000;93(2):279-81.

[5] Day JD, Kellogg JX, Tschabitscher M, et al. Surface and superficial surgical anatomy of the posterolateral cranial base: significance for surgical planning and approach. Neurosurgery 1996;38(6):1079-84.
[6] Avci E, Kocaogullar Y, Fossett D, et al. Lateral posterior fossa venous sinus relationships to surface landmarks. Surg Neurol 2003;59(5):392-7.

[7] Hwang RS, Turner RC, Radwan W, et al. Relationship of the sinus anatomy to surface landmarks is a function of the sinus size difference between the right and left side: anatomical study based on CT angiography. Surg Neurol Int 2017;8:58.

[8] Bozbuga M, Boran BO, Sahinoglu K. Surface anatomy of the posterolateral cranium regarding the localization of the initial burr-hole for a retrosigmoid approach. Neurosurg Rev 2006;29(1):61-3.

[9] Alper F, Kantarci M, Dane S, et al. Importance of anatomical asymmetries of transverse sinuses: an MR venographic study. Cerebrovasc Dis 2004;18(3):236-9.

[10] Tansirisithikul C, Sitthinamsuwan B, Srirabheebhat P, et al. Anatomical study of relationship between Zygoma-inion line and transverse sinus in dried Thai human skulls. J Med Assoc Thai 2017;100(Suppl 3):S54-S8. 